\title{
QUALITY CONTROL AND IMPROVEMENTS MECHANISM OF STUDY FIELD - FOCUSED ON PROFESSIONAL STUDY FIELD
}

Zdeněk Vondra ${ }^{\bowtie}$

${ }^{\square}$ Graphic and Multimedia Laboratory, Faculty of informatics and statistics, University of Economics, Prague, nám. W. Churchilla 4, Praha, 130 67, Czech Republic, +420 777033 438, zdenek.vondra@vse.cz

Highlights

- Description of the influences on quality control and continuous improvements of study field.

- Case study of the continuous development mechanism for study field Multimedia in Economic Practice.

- $\quad$ Proposal of specific control mechanisms for application on study field.

\begin{abstract}
Quality control mechanism that allows long term improvements of a study field or a study program is necessary for good functioning of educational institution or department in actual nature of competitive universities' environment. This paper focuses on quality control mechanisms in general and more closely on professional study fields. The professional study fields have been settled in Czech higher education by approving the amendment to the Higher Education Act. This brings new need for control and improvement mechanisms based more on connection to industry practice than on academic publications. The aim of this paper is to explain the importance of gathering information from contact with study field's stakeholders. These information lead to form appropriate improvements implemented on time. In the case study, there are presented examples of gathered findings and how they are being handled. They include the student's expectations that underrate theory although it is needed for basic insight to the industry. The students are also motivated to start their own business. What this paper brings is the proposed continuous development mechanism that helped to improve the bachelors study field Multimedia in Economic Practice and also the general recommendations that should help to any other study field.
\end{abstract}

\author{
Article type \\ Full research paper \\ Article history \\ Received: October 29, 2016 \\ Received in revised form: December 2, 2016 \\ Accepted: December 8, 2016 \\ Available on-line: April 10, 2017
}

\section{Keywords}

Continuous development, control mechanism, education, Multimedia in Economic Practice, professional study field, quality

Vondra Z. (2017) "Quality Control and Improvements Mechanism of Study Field - Focused on Professional Study Field", Journal on Efficiency and Responsibility in Education and Science, Vol. 10, No. 1, pp. 16-23, online ISSN 1803-1617, printed ISSN 23362375, doi: 10.7160/eriesj.2017.100103.

\section{Introduction}

This paper is focused on identifying and defining systems and mechanisms of quality management of universities study programs and study fields. Closer focus of this paper is directed to professional study fields that became a new phenomenon in Czech education system. This kind of study has autonomic demands arising from their nature based on practical skills. Universities are free in setting up the content and in running study fields and programs on contrary to high schools or elementary schools. Universities can establish a brand new study field by passing the accreditation process. The rest of quality assurances are up to university. The question to be asked in this paper is how to control the quality of study field and also how to control the benefits for society from running it. This paper is trying to answer the question by proposing the big picture of quality control and the improvements mechanism followed by the set of tools for quality control of study field gathered by own authors research. These tools are followed by the examples of gained findings and by effects of the improvements that were done to manage the findings. Common problem of Czech schools in general is their taciturnity to practice and common society life. Relevance of this topic is perceptible in Czech universities environment by effort put in to projects like IPN KREDO (MŠMT, 2016) that is also highly focused on long term development of quality of universities programs and study fields. KREDO is the Czech abbreviation for quality, relevance, efficiency, openness and diversification of higher education in the Czech Republic.

In this paper systems and mechanisms of the quality control of professional study fields are described by the outputs of qualitative research made on University of Economics, Prague on its first professional study field that was developed in accordance to Bologna declaration. Observations, action research, surveys and case studies that were done in last five years brought findings about used tools, their combinations and effects of implemented improvements.

Aim of this paper is to discuss the system of quality control of study fields. This paper is focused on professional study fields. The system is understood from its client's point of view. It means employers and labor market that define specific needs of their organizations demanded from graduates. There is presented the case study of actual mechanism of continuous development of the professional bachelor's study field Multimedia in Economic Practice (MEP). The case study shows what outputs should be gained and how valuable they are in purpose of improving the quality of study field. From the description of control mechanism in general and from the case study there are derived the general recommendations for study fields' managers. The findings presented in this paper are based on five years of research of the study field's content and its impact on study field's stakeholders especially students, graduates and employers. In this paper in order to make a reference and inspiration for other study fields' long term development there is presented the mechanism of getting data answering the long term questions evaluating relevancy of the study field to industry demands.

This paper is structured into the eight parts. The first part is the introduction that presents the studied situation. In the second part there is presented professional study 
field concept in general and the situation about setting this term into the Czech law. The third part presents the research methods and the nature of reached data and findings. The fourth part discusses the general concept of the quality control mechanism of study fields. The sixth part describes the specific studied example and its mechanisms of continual development, especially the processes of gathering information, and the mechanism of their evaluation and implementation of improvements. The seventh part presents findings and discussion in accordance to the asked questions followed by general recommendations arisen from the case study. These recommendations include proposed categories of control mechanisms. The final eighth part is conclusion which generalizes the outputs of the paper.

This paper extends the study that has been presented on conference ERIE 2016 called Continuous development of professional study field (Vondra, 2016). The study is extended in definition of wider context of the problem and pointing out the general system of study fields' quality control.

\section{Professional study field}

After the Bologna declaration in 1999 higher education in Europe have been changed and normalized due to the synchronization and better movement of students between European universities. Between many of the synchronization agendas like credit systems there have been explained the meaning and relationship between bachelors, masters and doctoral degree of higher study. Three years long bachelor degree should be practical in context of the field. Two years long master degree should be more theoretical. Doctoral degree is a level of science work. New term that has been agreed in Europe environment was the professional study. This kind of study has no ambitions in science or in theoretical improvements but in professional mastery to professions that require graduation in bachelor university level.

The bizarre situation happened in the Czech Republic. Universities that ran five yearlong master degrees did not rebuilt the study plans, but just divided these plans to two three and two years long parts. In other words a graduate of three years long bachelor degree had $3 / 5$ knowledge and skills from a study program but did not completed profession profile. This situation led to many initiatives and discussions that followed the development of new Higher education act. Finally in 2016 the term professional study field has been settled in this document. The situation of developing and approving the new Higher Education Act has continually been complicated by political situations and whole process has been rapidly slowed down. Real progress in this intention has finally come in 2016 in the final form of the amendment to the Higher Education Act which brought the term professional study field to practice. In January 2016 Czech chamber of deputies has approved the amendment to the Higher Education Act. The amendment includes for the first time in Czech law history the term professional study field and defines its meaning in the system of higher education and its specifics in the process of accreditation (Zákon č. 111/1998 $\mathrm{Sb}$.).

Professional study fields are based on the contrary to academic study fields more on practical knowledge and skills than on theories and variety of different perspectives. This kind of study was derived from academic fields as a reaction to the demands of labor market. For universities it is a step towards the real practice that will be much deeper than just study field (Sam, van der Sijde, 2014). Professional study fields fulfil the gap between academic higher education and professional society demands by going straightly towards employability of graduates that is supported by European Science Foundation (Brennan 2008). Professional study fields are focused more on handling practical skills and procedures. Professional study fields often labelled professional schools or professional studies are regularly linked to practice communities or industry professionals (Stark, 1998). Academic study fields teach students to develop their points of view and to understand terms in wider consequences. The fact that professional study fields are circumscribed on narrower service and technical roles led to their underrating by academic study staff. After approving the amendment to the Higher Education Act in Czech Republic (PSP ČR, 2016) professional study fields are officially an opportunity for universities to develop in close linkage to industry professionals and a new opportunity for students to study. Professional study fields are supposed to be taught close to the practice and must react to the actual situation of the industry more than common academic study that base on long term theories and paradigms. This situation creates a demand for a new kind of a quality control mechanism and continuous development tools. A need for regular updates of study content allows guaranteeing an appropriate level of relevant knowledge and skills. That means continual revisions of study plan, its concept as a whole and of the content of individual courses as well. The main goal is employability of graduates. This paper should be understood as the tool for improving measurements of the University-to-Work transition Success (Zákon č. 111/1998 Sb.).

\section{Materials and Methods}

As it was mentioned in the introduction in this paper the systems and mechanisms of the quality control and improvements of professional study fields are described by outputs of the qualitative research made on University of Economics, Prague on its first professional study field that was developed in accordance to Bologna declaration years before the amendment to the Higher Education Act. The research was done in last five years. It brought findings about used tools, their combinations and implemented improvements. The research was done in accordance to the qualitative research standards set by Myers (2013) and Yin (2009). The research was based on the case study made on professional study filed Multimedia in Economic Practice in comparison to other study fields on the university or similar study fields outside the university.

\section{There were used following methods:}

- Analysis of data from the study information system (numbers of students in grades, numbers of students on individual courses, graduates in courses, students written evaluations)

- Survey research asking students about relevancy and their opinion about courses and the whole study plan of the study field

- Interviews with study fields stakeholders on the graduates profile, the study plan and the teaching methods

- Action research of implementing the new mechanisms and improvements during last 3 years

- Observations and comparisons of improvements effects by feedback from the study fields stakeholders and the impact on the graduates profile

Relevant data and information are mainly qualitative in nature. 
They are collected from the integrated study information system and from the interviews and discussions with study field's stakeholders. The ongoing research consists of surveys, interviews, observations and discussions and so far was conducted on more than 250 students, 30 industry professionals, 5 similar university programs and 7 important companies from the case study's industry environment. Data were collected and processed by looking for relevant contexts and by using additional methods like mind mapping, comparisons and looking for similarities.

\section{Control mechanism in general}

At first there should be presented the hypothesis of how the control mechanism should work in general. We are going to set up the big picture for the better understanding of the case study. If we look on the study field as a system, there should be identified relevant elements for control of quality. The study program or study field is made by its stakeholders, by the content and the facility where it is run. This basis is confirmed by information from the Russian project EQUASP where similar elements are used to set up the quality control (Pugach, Syrtsova, Tokmakova, 2015). The stakeholders are applicants, students, graduates, pedagogues, guarantees, industry professionals, employers, faculties or university offices, founder, ministry, accreditation office and public. The content is knowledge and experience provided to students from research works, study materials and pedagogues know-how. Facilities of the study are all material assets used for running the study.

After use of the CATWOE analysis to identify the elements of the relevant system (Checkland, Scholes, 2001) there was found following findings. The clients of the study field are students and employers at the first stage and whole society at the second stage. The actors are all mentioned stakeholders. The transformation is to transfer knowledge and experience from pedagogues and industry professionals to students with intention to support the society's needs represented by situation on labor market. The worldview is that universities have to provide education that will prepare graduates to work in practice on specific occupations. The owner of the process is a founder but the responsibility is on study field guarantee. The most important environmental influences are demographic situation, concurrence between universities, demands of employees and industry professionals, law, ethics and cultural influences. In the case of professional study fields the law and the changes in Higher Education Act are very important. Now there is described the overview of the study fields system.

Now the research paper is going to focus on the mechanisms of quality control. There will be mentioned and described these mechanisms in general and then the mechanisms in case study. The basic control mechanisms were setup by the law. They are connected to the accreditation process and funding algorithms. These mechanisms are not enough specific for practical improvements use. They only validate if the study field matches the common defined criteria. These criteria were setup by the academics and legislatives. Accreditation process has its own rules based on science publications and several other factors (qualification of pedagogues, mobility). These factors follow government politics of universities funding and intentions in science.

After the observations and interviews there should be presented following extension. In practice the quality of university is often verified by the graduates' abilities to fulfill labor market needs. These affect the brand of the university and make its image to both employers and attendants. By the connection of the law and the practical quality control mechanisms there should be presented following list of observed general control mechanisms:

\section{- Accreditation process}

- Science publications, qualification of pedagogues, mobility

- Cooperation with industry professionals

- Employers feedback

- Medial prestige and public popularity

Cooperation with industry professionals, employers' feedback, prestige and public popularity of study field are not considered in any formal process that affects the assets of universities. That should be considered as the big problem allowing existing study fields with no benefit for the society while they match the accreditation criteria. In discussed situation the formal process should be replaced by the market principles and impact of quality to study field promotion and awareness. In this area there is a big need of change of control mechanisms in general to make bigger benefit to the labor market.

After a general explanation of the study fields control mechanisms situation there is presented the case study of professional study field MEP and its continuous development mechanism. There are presented the specific tools that are used for improving its quality. The case study shows and discusses what outputs were done by this mechanism and how they improved the study field. In connection with the previous text the case study should be considered as the complex and long term action research experiment. The used control mechanisms were selected in order to meet labor market needs. In the terminal part of this paper the findings from the case study are generalized and taken to general recommendations.

\section{Case study of the professional study field}

The professional study field Multimedia in Economic Practice teaches its students about production of audio-visual communication tools such as text, computer graphics, digital photography, animation, digital video and sound in accordance to Tay Vaughan's (2008) multimedia interpretation completed by web skills and theoretical cognitive background (Mayer, 2009). The study field teaches the abilities of doing analysis, conception, design and processing of multimedia content, for the realization of functional communication (Vondra, Vltavská, 2014). It prepares students for their future occupation or their own business in advertising, media companies, web or application development or development of graphical user interfaces and its content. The study field is now settled and being taught for five years. Due to its status to be the first of its kind on the university it has to deal with new kinds of tasks about principles of actualization and continuous development. Graphic and multimedia laboratory of Faculty of informatics and statistics at University of economics, Prague in 2009, as first at the university developed and started the accreditation process of the new professional bachelor's study field in accordance to expected future progress of tertiary education. The study field was intended from the beginning as professionally oriented and without relation to any master degree. Its conception was 
based on corresponding principles from White Paper on Tertiary Education that supposed to be a future base of the new Higher Education Act.

The study plan is divided into several areas (with percent share of credits in study plan):

- Theoretical courses $13 \%$

- Practical production courses 38\%

- Conceptual and process courses $9 \%$

- $\quad$ Soft skills and language courses $13 \%$

- Economic courses 27\%

Personal experience of pedagogues and industry professionals who were in touch with students and graduates has led to establish the long-term questions and discussion initiated by the need to meet the industry demands for the graduate profiles. This kind of continual improvement process should bring continual innovations needed to keep the study field actual and linked to the industry. Demands for topicality and connection with practice are the basics of the mechanism of continuous development of the professional bachelor's study field mentioned in this paper. The industry professionals in this paper are understood as both eventual employers of graduates and professional consultants or practice communities (Stark, 1998). In the following text is presented the actual model of the mechanism and the outcomes and findings gained from its use.

Continuous control and development mechanism of the study field is based on gaining data, their evaluation and doing appropriate actions or improvements as soon as possible. It should be understood as a control mechanism with quick implementation plan. The aim of the research presented in this paper is to improve the setup of the study field by asking the questions to the stakeholders with different perspectives to evaluate the setup and to try to find issues to optimize or improve. Main questions that are asked in the research are:

- Q1: What are the occupations of graduates or students?

- Q2: What are the future plans for occupation or study of graduates and students?

- Q3: What are the evaluations of knowledge and skills graduates gained during their studies?

- Q4: What are the evaluations of individual courses contents?

- Q5: What are the evaluations of the study field as whole, how does it meet industry needs?

These questions were asked to study field's stakeholders in several ways. In the following list there are presented used continuous control and development mechanisms for answering the questions:

- Students success in the study taken from the information system

- Survey about relevancy of courses to student future occupations

- Activities on individual courses

- Mentoring of graduates

- Discussion with graduates

- Opinion conference with students

- Discussion with pedagogues, industry professionals and employers

- Competitions
- Work opportunities

- Practical workshops with industry professionals

- Comparison with students from different universities on mixed workshops

This part of the paper follows the list of used continuous development mechanisms and explains them.

1) Formal success of the students in the study is taken from the information system. It provides statistical data like number of students, number of graduates. For more it provides success rate of students at individual courses, credits and points gained in each course. These data serve for understand of quantitative scope. From this system it is also possible to get basic qualitative data like students' opinions on pros and cons and overall thoughts about individual courses. The students are motivated to fulfil these surveys after each semester by getting better position in the registrations of courses for next semester so the answer rate is nearly $50 \%$. This mechanism can show important information about difficulty or likeability of the individual courses. If some of the courses would be pointed by students as irrelevant or unwanted, it is possible to identify the cause by comparison with other courses. This service is provided by the university.

2) In 2014 the survey research has been conducted on 70 students to examine of the meaningfulness and structure of courses taught, in relation to the prospective profession of graduates, their previous experience and success in their studies (Vondra, Vltavská 2014). Outputs of this research have shown how the students see individual courses relevancies to their future occupation. Several are mentioned in the Results and Discussion part of this text. The main output was that practical courses were marked as relevant by students, even if they are not connected to their wanted future occupation. This was considered as the significant problem in motivation to study on professional study fields. Students expect practice.

3) The monitoring activities on individual courses bring data about occupations and future plans. They are gathered by three interviews with each student during his study. The first is passed during the presentations of first semester projects and is focused on motivations to study. The second checkpoint is the individual interview at the end of third or fourth semester (in the half of study) in the course Management of Multimedia Projects. Students are asked about their planned occupation and about their actual skills. It happens during examination where their conceptual and process knowledge of production of media outputs is tested. At this time two thirds of students know what career they want to pursue. The final checkpoint is passed in final course the Multimedia Project Seminar.

4) Mentioned final course of the study field is based on team project that has impact to practice (with real client or realization for public audience). The information from interviews is the first gained value, but the second is that approximately one or two projects a year are heading to form a real business in future. These attempts formed several successful start-ups and also one advertising agency. These projects that started at the university and continue their life in practice are a great opportunity for monitoring of the graduates and their transition to practice. The mentoring service has been offered to these by pedagogues in exchange for monitoring of their activities. Mentoring in general is often spoken relating to medicine study fields (Frei, Stamm, Budderberg-Fischer, 2010). It has importance for every profession. In the discussed case it is set up to meeting every 
two weeks for 90 minutes. Discussion is focused on processes and feedback for projects and is now settled with two projects.

5) Data about gained knowledge and skills, individual courses evaluation and evaluation of whole study field are gathered also from interviews and discussions with students and industry professionals. Once a year in autumn there is organized the discussion with graduates. Regularly, there are about 30 graduates and few actual students. Topics of the discussion are their actual occupations, their opinions about gained knowledge and skills, and the course settings of the study field. There the pedagogues are also presenting the plans for innovations of the study field for instant feedback.

6) The opinion conference is another way of discussion with actual students. It is based on more confrontational principle than the previous mentioned discussion. Students, key pedagogues and technical support are face to face in discussion to announce news in study plan and solve problems of both sides.

7) The main discussions with pedagogues, industry professionals and deputies of graduates are organized twice a year after the end of a semester. These discussions play the role of the most important forum of the study field's development. Every time the actual study plan is presented and all topics and questions are discussed. These discussions are regularly done with 20 to 25 participants, from which a half to two thirds is industry professionals and the rest are pedagogues. During these discussions, the opinions, insights and findings are matched together with industry practice and with the best practices of similar study fields in Europe. Information from study field's stakeholders is also gained by ad hoc individual interviews which work as preparation for this forum.

8) Competitions, work opportunities programs, practical workshops and mixed workshops are all variations of opportunities to compare skills and knowledge of students in time and with students and graduates from different universities. These mechanisms have to be followed by observations and interviews to be informed about the success or failure of students and to identify its main reasons. These mechanisms propose a big variety of tools from long term fellowship programs (for example academic programs of industry partners) or straight confrontations at single action or competitions. In case of the MEP there have been found the closely competitive study field and now both universities start to organize mixed workshops with 10 to 15 students from each university working on the same topic together. Results are fantastic in developing stronger networking and knowledge network but also from sharing the experiences. These events are one of the most benefit improvements. We also have a very good experience with collaboration with industry professionals on workshops where students can try to solve same problems as younger industry professionals. Like at the mixed teams with competitive study field events also in this case both students and pedagogues get a lot inspiration about the possible improvements.

Findings from all these mentioned procedures are implemented after validation on the main stakeholders' forum of the study field. Implementation into the study fields practice happen by a change of content of a specific course or by changing the study plan (adding or removing courses or changing their timelines). The accreditation process of courses allows implementing the changes within the following semester in line with main panel discussions organized after the semester.

\section{Results and their discussion}

This part of the paper presents the examples of mechanism outputs corresponding to the research questions and their proposed resolving. After the presentation of the answers to case study questions and following improvements there are evaluated the control mechanism tools and described basics to the general recommendations. Let's start with the questions and gathered outputs.

1) Answer to Q4: What are the evaluations of individual courses' contents? and Q2: What are the future plans for occupation or study of graduates and students? Problem: Production has overtaken insights and concepts: Industry professionals found out that students, and also some of the graduates, would produce multimedia outputs without deeper insight or understanding of the situation, led by false intuition. This situation is happening in average to two thirds of the students. Review in practice showed that both application of technology and of professional knowledge are needed (Paskin, 2013). After evaluating the problem, it has been found out, that it was related to insufficient number of evaluations of insights of students' work by pedagogues. It was revealed that students are able to develop appropriate insight but simply they do not want to. They would rather produce media outputs which they found more entertaining. Chosen solution was to ask students for insights and concepts more often so it becomes natural thing for them. It was implemented to the primary course of the study and also strengthened in other courses. There is prepared a brand new compulsory course about user experience, analysis and forming insights, which will start in winter semester 2016.

This situation was also perceptible in research about students' opinions about relevancy of courses to their future occupation. In this survey based research, it has been discovered that students regularly find almost all production courses relevant, even for occupations that do not need them all. At the same time survey research made in 2014 found out, that students prefer production courses over theoretical and economical and found them more relevant for their future plans even if they are not connected with field they want to do (Vondra, Vltavská 2014). These findings were matched together with opinions of graduates, who found the most theoretical course semiotics very important, especially by those who continue in study.

These findings helped to solve significantly important problem but the control mechanism has to be improved to catch these findings not only from graduates but also from students of all grades. As a solution there is planned to develop voluntary production service team made from students that will work as a simulation of industry practice. This will allow new possibility of monitoring of this problem. It is expectable that this will be the problem of professional study fields in general. Students attend this kind of study expecting practice, which lower their motivation to learn needed theory.

2) Answer to Q1: What are the occupations of graduates or students? Own business rather than being employed: Graduates would rather start their own business, than be employed. This surprising fact was confirmed by pedagogues and industry professionals from their interviews with graduates. 
Approximately $30 \%$ of graduates are employed, $20 \%$ study for master's degree and almost $50 \%$ of them works in their own business (measured by answers from 30 graduates of total 59). Fortunately, only one of the graduates was unemployed. These results will be reflected by modifying process courses towards implementation of deeper self-management skills, freelance and start-up business content. For now, freelancing course is being offered from time to time as a voluntary course.

Professional study fields have to deal with decision, whether they prepare students for employment or for doing their own business or both. This will create demand for specific economic and management knowledge and skills. This will be dependent on the university profile, if it is able to fulfil this demand well or if it would be better to outsource professionals for it.

3) Answer to Q3: What are the evaluations of knowledge and skills graduates gained during the studies? There is much more to teach in individual course: Many individual courses raised their need for hour allocation or to split them into two. This situation has to be evaluated very carefully, because changing one course's hour allocation could damage consistency of the whole study field. Students proved, that even though they are not taught the skills to maximum level, they can handle it and can professionally continue on in one detailed area (of course with individual effort, for example students that continue to study on master degree of cam-coding, movie directing or editing or marketing). On the other hand, there have been identified missing areas of study, which are social networks (identified by graduates) and user experience (identified by pedagogues and industry professionals).

When the study field prepares students for certain profession, there is a demand for knowledge and skills that are limited only by practice, which is very wide and should be seen in use. One course would then want to cover the whole area which would significantly enlarge its content. Situation with academic oriented courses is similar, but the use of wide knowledge is more hypothetical and connected to intellectual outlook, rather than practical use. Ideal state of professional study fields is to be very narrowly focused on one very specific profession which should be taught in detail. Despite mentioned findings, graduates of Multimedia in Economic Practice have very positive feedback from the practice. They, as well as industry professionals, appreciate the overlap of their knowledge and skills acquired in the study field and find it very useful.

4) Answer to Q5: What are the evaluations of the study field as a whole, how does it meet industry standards? This reaction present discussion on continuous development of professional study field concept in general: Presented concept of gathering information explains framework for evaluation and implementation of improvements that corresponds with studies about university-to-work transition success that are based on extrinsic and intrinsic outcomes of the study (Oliveira et al., 2016). In comparison, mechanism presented in this paper is focused just on work adjustment and not on social and motivational perspectives. On contrary, it presents more specific ways of collecting information and their evaluation. In the first place there have to be considered information from industry professionals who deal with graduates or who participate on pedagogical process. Experience from practice is the main ingredient which has to be followed by certain levels of insight understood by students. Students need to be able to answer the question: Why does it work? Pedagogues play the role of interface between practice and the university environment.

In creative activities, pedagogues should develop a way of how to better explain or simulate practice. By the research and science activities, they should participate on contract research or application projects to improve the industry practice procedures in general. Of course all these activities need their participation in practice, which is necessary in case of a professional study field. Next to this, the independent view of non-involved industry professionals is also very valuable and needed for better evaluation. In the second place, after industry professionals and pedagogues, there are graduates who bring the information about their integration into the industry practice. Their experience can bring relevant findings, but more about knowledge and skills for integration or starting a business than about the setup of the whole study field. Graduates become professionals after few years of industry practice and then they will be able to critically evaluate the study field setup as a whole. In the third place, insights from actual students are valuable in evaluating individual courses and the pedagogical process, but not in general. Students do not have appropriate experience from industry practice. It happens a lot, that in the practice, or during their studies on another school, they found out that things they considered unnecessary became very helpful.

\section{Discussion in general}

The questions asked in the case study are typical for professional study field. In case of academic study fields there would appear also questions about long term research plan of the pedagogues or international transfer of knowledge. Professional study fields are narrower in variety of topics and may become also geographically narrower in case of strong connection to local industry partners. At this place it is appropriate to evaluate proposed quality control mechanisms of study fields.

Accreditation process is the basic tool of meeting the criteria setup by the law. It should be understood as the license that is not assuring the success. In all cases it has to be passed. For the professional study fields in the Czech Republic is positive that the actualized Higher Education Act provide the status of professional study that changes the structure for accreditation criteria. Science publications, qualification of pedagogues and mobility are connected to the accreditation process and also play a big role in funding. Professional study fields are waiting for the mechanism of integration of practice involvement and quality connections to industry professionals.

Data from information system and surveys about study plan are very useful for basic overview about actual state and the scope of the study field. Study field is qualitative entity and these data need to be validated by observations and interviews to get to actual issues. They are the important base to follow the relevant lines of questions.

Any opportunities to compare students' knowledge and skills are very helpful for pedagogues to understand and rate their work. Best way is to mix students with students from competitive study field to see the differences and similarities or to face them to young industry professionals.

Discussions with students and graduates in any way are profitable to get information about subjective opinions. If these discussions are done in bigger scope, it can provide o lot of findings that 
should be connected with data from information system to decide what proposals should be made. It is recommended to not listen to students on $100 \%$ because significant part of them is not decided about their future occupation and they do not know what knowledge and skills they will need in the future. In this case they care more about their comfort and simplicity of study.

Mentoring of graduates is very useful in way of helping the graduates to become successful in practice and also for gaining specific deep information about study plan settings. Barriers of mentoring are its costs of time and thus money. Mentoring is a big benefit for both sides but have to be supported by solving the problem of costs.

Cooperation with industry professionals and employers feedback is the main indicator whether the graduates' skills and knowledge meet labor market needs. For pedagogues it is significantly important to be closely in contact with industry professionals for example by the regular meetings to be able to react to the real needs of the industry labor market demands. It is recommended to organize meeting of all main stakeholders in the way of discussion with pedagogues, industry professionals and employers. The work on feedback, evaluation and creating the concept on improvements is fastest in touch with all relevant stakeholders groups.

Prestige and public popularity in long term is based on quality of product that universities offer. No marketing or communication activity would replace it in long term horizon. If the department that run the study field has good outputs in science, is good in industry partnerships and have a high credit for employers, it is easy to get high rank in popularity and prestige. Tricky part of this feature is popularity of study field's orientation in general. At the end the popularity and prestige are the most substantive argument to select study field by attendants.

As a conclusion of this paper there are provided main categories of control mechanisms that would be executed customized for a specific study field by specific corresponding tool. In the list there are reorganized the mechanisms from the previous part as the reaction to the case study and the discussion of its findings. Recommended categories of study fields' quality control mechanisms are following.

- Accreditation and funding principles parameters

- Evaluation of content, science, projects

- Data about study

- Students opinions

- Students knowledge and skills comparisons

- Graduates opinions

- Discussions with industry professionals and employers

Data about study, students' opinions, students' knowledge and skills comparisons, graduates opinions serve to gain data for further validation and for making proposals of improvements. Discussions of pedagogues with industry professionals and employers is the main forum for evaluation of the proposals and selection the actions to implement. Accreditation and funding parameters work as formal control of achieving demanded standards by education governance. Content evaluation works in way of getting funding from accessible opportunities and should be supported by following steps. For comparison Subbaye and Vithal (2017) identified in their study focused on evaluation of teaching and eventual promotion decisions at a South African university following ten criteria: rationale for teaching, teaching methods, postgraduate supervision, assessment, student evaluations, peer evaluations, ongoing study of higher education, developing courses, sharing teaching experiences and special recognition of teaching. There should be recognized similarities and inspirations to underline importance of mentoring (or postgraduate supervision), sharing experiences in discussions and students opinions evaluations.

\section{Conclusion}

This paper presented the concept of quality control mechanism of study field. There was discussed the general level and then the specifics of professional study fields. As the case study there were showed principles how the professional bachelor's study field Multimedia in Economic Practice is being continuously developed and innovated, how the information is gathered and how the improving process is working. Main benefit of this work is revealing universal principles of continuous development and relevancy of information from stakeholders groups. Stakeholders are applicants, students, graduates, pedagogues, guarantee, industry professionals, employers, faculty or university office, founder, ministry, accreditation office and public. Suggested way of continuous development of professional study field is to collect data about individual courses and the knowledge and skills that are given to students. Next data to collect are about students and graduates and their occupations or businesses and finally the data about the study field as whole. Methods used for collecting the data should be interviews or surveys connected with observations by various study field stakeholders. One thing is what people say but another thing is what they really do. This combination should clarify how the students and graduates see themselves, how they are seen by professionals and how it is all seen by pedagogues. If it is possible to do long term monitoring of graduates in practice, it would be very valuable and helpful and should bring a deeper insight. Opinion of industry professionals is the most important indicator because they represent employers. All gathered information should be discussed in detail with industry professionals to find potential effect on graduates' integration to the industry. The mechanism of transforming significant findings to possible improvements, choosing and evaluating the best form, realization and implementation should be done as soon as possible due to the potential changing environment in the industry. Maximal time to this would be six months.

The general recommendation for professional study fields and study fields in general arising from this text is to critically follow all relevant signals and information to improve and implement them as soon as possible. Quality control should be done by mechanisms identified as accreditation and funding principles parameters, evaluation of content, science, projects, data about study, students opinions, students' knowledge and skills comparisons, graduates opinions and discussions with industry professionals and employers.

What to do next? In case of general point of view there should be collected more information and best practices to continually develop the mechanism that should be implemented to support real needs of the labor market. In case of professional study fields when the amendment to the Higher Education Act is fully implemented with professional study field category and also with institutional accreditation we can expect development of new study fields that will show more about their nature across industries. That would bring more possibilities to compare them 
with classic academic study fields and think about their setup for individual occupations. The only obstacle from the past is seeing of bachelor's degree title in Czech society as being not enough but time will make it better.

\section{Acknowledgements}

This paper was processed with contribution of long term institutional support of research activities by Faculty of Informatics and Statistics, University of Economics, Prague.

\section{References}

Brennan, J. (2008) Higher education looking forward: An agenda for future research, Strasbourg: European Science Foundation.

Checkland, P. B., Scholes, J. (2001) 'Soft Systems Methodology in Action', in Rosenhead, J. and Mingers, J. (ed.), Rational Analysis for a Problematic World Revisited, Chichester: Wiley. Frei, E., Stamm, M. and Budderberg-Fischer, B. (2010) 'Mentoring programs for medical students - a review of the PubMed literature 2000 - 2008', BMC Medical Education, Vol. 10, No. 32. http://doi.org/10.1186/1472-6920-10-32

Mayer, R. E. (2009) Multimedia learning, 2nd edition, Cambridge: Cambridge University Press.

Myers, M. D. (2013) Qualitative research in business and management, Sage.

Oliveira, M. d., Melo-Silva, L. L., Taveira, M. C. and Grace, R. C. (2016) 'Measuring university-to-work success: development of a new scale', Career Development International, Vol. 21, No. 1, pp. 85-104. http://dx.doi.org/10.1108/CDI-04-2015-0051

Paskin, D. (2013) 'Attitudes and perceptions of public relations professionals towards graduating students' skills', Public Relations Review, Vol. 39, No. 3, pp. 251-253. http://dx.doi. org/10.1016/j.pubrev.2013.01.003

Pugach, V., Syrtsova, E. and Tokmakova, O. (2015) 'Online model of education quality assurance equasp implementation: Experience of Vyatka state university', International Journal for Quality Research, Vol. 9, No. 3, pp. 513-526.

Sam, C. and van der Sijde, P. (2014) 'Understanding the concept of the entrepreneurial university from the perspective of higher education models', Higher education, Vol. 68, No. 6, pp. 891908. http://dx.doi.org/10.1007/s10734-014-9750-0

Stark, J. S. (1998) 'Classifying Professional Preparation Programs', The Journal of Higher Education, Vol. 69, No. 4, pp. 353-383. http://dx.doi.org/10.2307/2649270

Subbaye, R. and Vithal, R. (2017) 'Teaching criteria that matter in university academic promotions', Assessment and Evaluation in Higher Education, Vol. 42, No. 1, pp. 37-60. http://dx.doi.org /10.1080/02602938.2015.1082533

Vaughan, T. (2008) Multimedia: making it work, 7th edition, New York: McGraw-Hill.

Vondra, Z. and Vltavská, K. (2014) 'Revision of Course Settings in Multimedia in Economic Practice Study Field', Proceedings of the 11th International Conference on Efficiency and Responsibility in Education (ERIE 2014), Prague, pp. 898-904. Vondra, Z. (2016) 'Continuous development of professional study field', Proceedings of the 13th International Conference on Efficiency and Responsibility in Education (ERIE 2016), Prague, pp. 666-674.

Yin, R. K. (2009) Case study research: Design and methods, Sage publications.

MŠMT (2016) IPN KREDO, [Online], Available on: http:// kredo.reformy-msmt.cz [28 Oct 2016].

Zákon č. 111/1998 Sb., o vysokých školách a o změně a doplnění dalších zákonů (zákon o vysokých školách), ve znění pozdějších předpisů, a některé další zákony [the amendment to the Higher Education Act 2016]. In: Sbírka zákonů 137/2016, částka 53. ISSN 1211-1244. 